\title{
HOW PUBLIC ORGANISATIONAL STRUCTURES INFLUENCE SOFTWARE DEVELOPMENT PROCESSES
}

\author{
Mohammed A. Bindrees, Robert J. Pooley, \\ Idris S. Ibrahim and Diana S. Bental
}

School of Maths and Computer Sciences, Heriot-Watt University, Edinburgh, UK

Received 2014-05-31; Revised 2014-06-06; Accepted 2014-09-20

\begin{abstract}
Software applications are developed differently based on each organisation's needs and requirements. Software projects are fundamentally based on three considerations (time, cost and quality) each of which is affected by organisational factors. Both Project Management and Software Engineering have emphasised the role of organisation structure on the quality of the deliverable software applications, recognising that organisation structure influences flexibility, reporting relationships and conflict management during the software development lifecycle. This study reports on aqualitative study which highlights the impact of three organisation structures on software development processes in public organisations and proposes a new organisational model. Semi-structured interviews were conducted with three types of participants, a within-case analysis performed to identify themes and as a result a new organisational model was proposed and validated through further interviews. Outcomes showed that combining two existing structures (Functional and Matrix) into one new structure "Independent Project Management Office" (IPMO) would help to overcome administrative obstacles and conflicts in the public sector. The IPMO structure would augment the flexibility and interaction level among software development stakeholders from the perspective of organisations' leaders.
\end{abstract}

Keywords: Organisation Structure, Software Development, Matrix, Pure Project, Conflict Management

\section{INTRODUCTION}

Positive interaction amongst software project stakeholders has been credited for the success level in these projects (Petersen and Wohlin, 2010). This interaction can be influenced by many factors such as the type of software, users and organisational structures involved (Sommerville, 2011). Organisational structure refers to "the formal aspect of an organisation's functioning: Division of labour; hierarchical authority; job descriptions" (Beynon-Davies, 2002). Relationships between employees, process and management can be shaped by the structure of their organisation. Moreover, organisational structure has an impact on the choice, design and development of information systems (AlHalak et al., 2010; Baxter and Sommerville, 2011;
Beynon-Davies, 2002). The relationship between Organisation structure and innovation performance in a large sample of UK small and medium-sized enterprises was observed by Cosh et al. (2012), hence, they show that decentralised decision-making, supported by a formal structure and written plans, supports the ability to innovate (Cosh et al., 2012). Most organisations achieved limited success and many restructures which involved considerable social costs and limited gains in effectiveness (Mcmillan, 2001). Interaction between Information Systems (IS) and organisation structure is seen mutually from each part. The structure of particular organisation can change IS design and conversely, IS outcomes can change the structure of the adopted organisation. Doherty et al. (2010) Champion and Wang state that the implementation of Enterprises Resources Corresponding Author: Mohammed A. Bindrees, School of Maths and Computer Sciences, Heriot-Watt University, Edinburgh, UK 
Planning technology (ERP) and the strategic orientation of the host organisation are both likely to modify the structural design. The study by Doherty et al. (2010) proves the impact of ERP on organisational structure, but conversely, organisation structure can impede the development of software applications such as ERP (Chen et al., 2009). According to Beynon-Davies (2002), three aspects should be taken into account before adopting a particular structure: (1) Division of labour (2) Chain of command and control (3) Specification of rules and procedures (Beynon-Davies, 2002). Although these aspects are very important in practice, organisation size and policies might impede the choice of particular structure. In bureaucratic organisations, these aspects can be witnessed clearly. Large organisations have shown more rigid and constant structure by adopting a vertical hierarchy for commands and information flow, in which commands flow down the hierarchy while feedback, information and reports flow up the hierarchy.

Many large organisations have changed their structures to a multi-divisional structure in order to cope with vast development competition. Furthermore, modern organisations have made more efforts to give some units within many divisions more autonomy and trust in making their own decisions (Beynon-Davies, 2002).

\section{PROJECTS ORGANISATION STRUCTURE MODELS}

Since the emergence of Bureaucratic organisations in the beginning of $19^{\text {th }}$ century, the influence of organiastion structure on workers was wittnessed practically, most public organisations adopt this bureaucratic model because of the perceived benefits in organising work processes in a hierarchical flow. Moreover, Fayol in 1916 developed classical management theory by identifying a number of principles that have impacted on the structure of an organisation. These theories included the division of work into compartments and the unity of command, principles which are still relevant today (Martin, 2010). Although this structure is considered as an inflexible and rigid approach (Kanter, 1984), it is effective on logical workflow. Managing the structure's viability and flexibility is very important for the following reasons (Maylor, 1996):

- Responsibility and authority definition

- Reporting arrangements
- Determining management overheads (costs)

- Matching the structure behind the organisational culture

- Determining the stakeholders in project activities

Moreover, many scholars have pointed out the importance of organisation structure in shaping the work attitudes and performance (Burns and Stalker, 1961; Miller, 1986; Mintzberg, 1989). In addition, Ashton states that there is a strong association between organisation structure and distribution of knowledge and information in workplaces (Ashton, 2004). Empirically, organisation structure models need more consideration of two important issues, (1) Determining the project level to achieve satisfactory group dynamic level (2) The fitness between the parent organisation and the new selected structure (Moore, 2002). Martin (2010) has listed the most common structures found in practice such as:

- Entrepreneurial structures: Typically found in a small organisation where the business owner is playing the dominant role in his organisation's processes

- Product-based structures: In this type, all the organisation processes focus on certain product and most of the organisation's goals support the production of this target

- Process-based structures: Sometimes called the functional approach (described below)

- Matrix and project-based structures: This is an integration of both functional and product responsibilities into people's activities

- Flexible organisations: This emphasises flexibility in employment and working circumstances

- Flatter organisations: This includes few levels between high management and the lowest employees' level

- Virtual and federal organisations: This structure includes collaboration between the original organisation and its alliances in order to achieve unachievable targets single-handedly (Martin, 2010)

These models describe the structure of a very wide range of organisations, both public and private sector and they describe them from different perspectives. From the perspective of project management in public sector organisations there are three main models: Functional organisation, Pure Project structure (with dedicated project teams) and Matrix organisation (Larson and Gray, 2011). 


\section{Firstly}

A Functional Organisation structure as shown in Fig. 1 attempts to link each project directly to the associated functional department in the organisation. The functional department's staff are highly involved in the project's outcomes; thus, the department head would take the role of project manager or team leader, even if his experience is not sufficient in some aspects of the projects (Larson and Gray, 2011; Mcmillan, 2001; Moore, 2002). Moreover, each department might be involved in leading several projects at the same time based on the importance of this department.

\section{Secondly}

In Pure Project organisation (also known as dedicated teams structure) as shown in Fig. 2, the organisation tries to create a new, exemplary, independent working environment that is supplied with efficient staff members and project managers in order to implement its projects with a high level of efficiency and professionalism (Larson and Gray, 2011). This model has many advantages in terms of the quality and autonomy level but some negative points have been reported such as cost,post-project transition and workers internal strife. Accordingly, each department in parent organisation needs to communicate with the project team through one formal channel such as an allocated coordinator between these two environments.

\section{Finally}

Matrix structure was defined by Ford and Randolph as "any organisation that employs a multiple command system that includes not only a multiple command structure but also related support mechanism and an associated organisational culture and behaviour pattern"(Ford and Randolph, 1992). A Matrix structure tries to combine project organisation with the parent organisation in order to enable a project manager to control what is to be done by the individuals and groups assigned to each project as shown in Fig. 3, while they are doing their daily tasks at their places (Larson and Gray, 2011; Moore, 2002). A Matrix structure has two dimensions in terms of its command control and operations: The horizontal dimension, which is overlaid upon organisations' functional departments and the vertical dimension, which is continuous with the project line (Larson and Gray, 2011). Moreover, Matrix structures can be of three types (Weak Matrix, Balanced Matrix and Strong Matrix) based on the relationship strength between the project manager and the functional department.

In the case of multiple co-located projects, some organisations create a dedicated department to manage these projects called a Project Management Office (PMO). A PMO is considered as an organisational entitywith the facility to provide services and organisational focus in core and supporting areas of project management (Hobbs et al., 2008; Rad and Levin, 2002). In addition they state that organisation needs to be re-confederated in order to implement PMO effectively. Rad and Levin (2002) state that the main organisational roles for PMO are usually project portfolio management; best practice in project management; PM standards and methods; consulting; monitoring; training; and quantitative objectives for continuously improving enterprise project management processes. More generally, PMOs are created to manage multiple projects in harmony with organisation's policies and strategies (Hobbs et al., 2008).

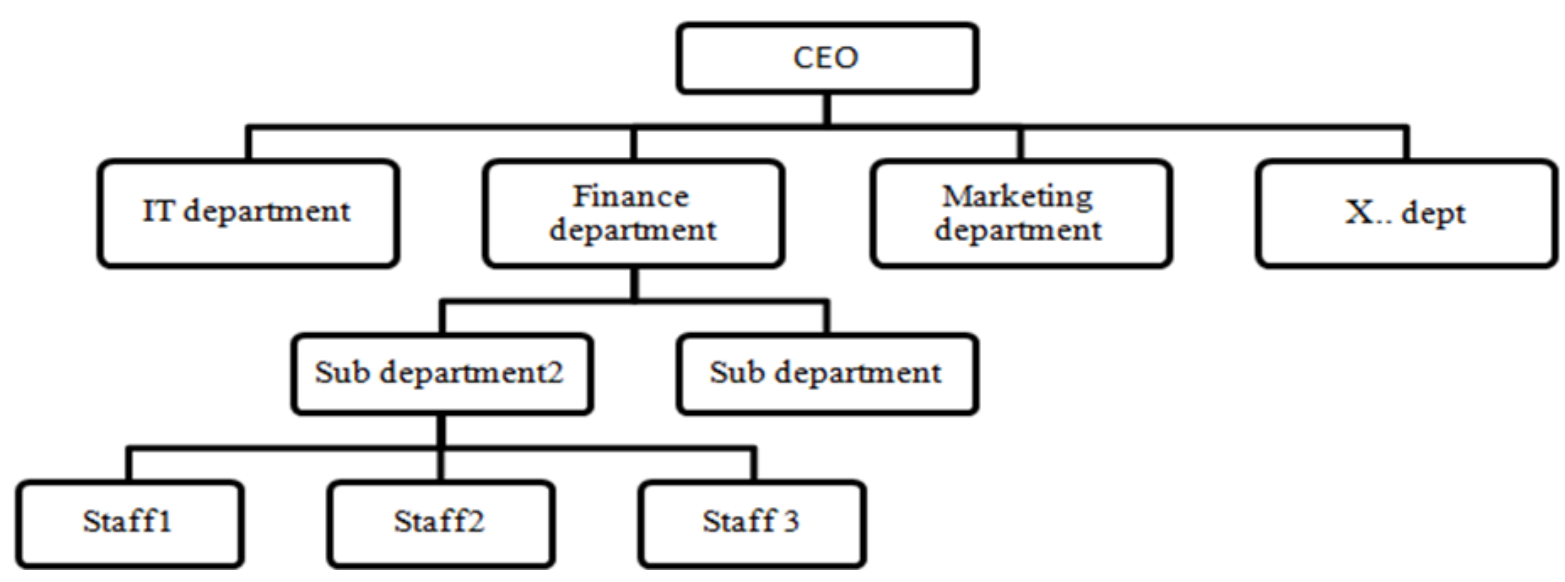

Fig. 1. Functional organisation structures (Larson and Gray, 2011) 


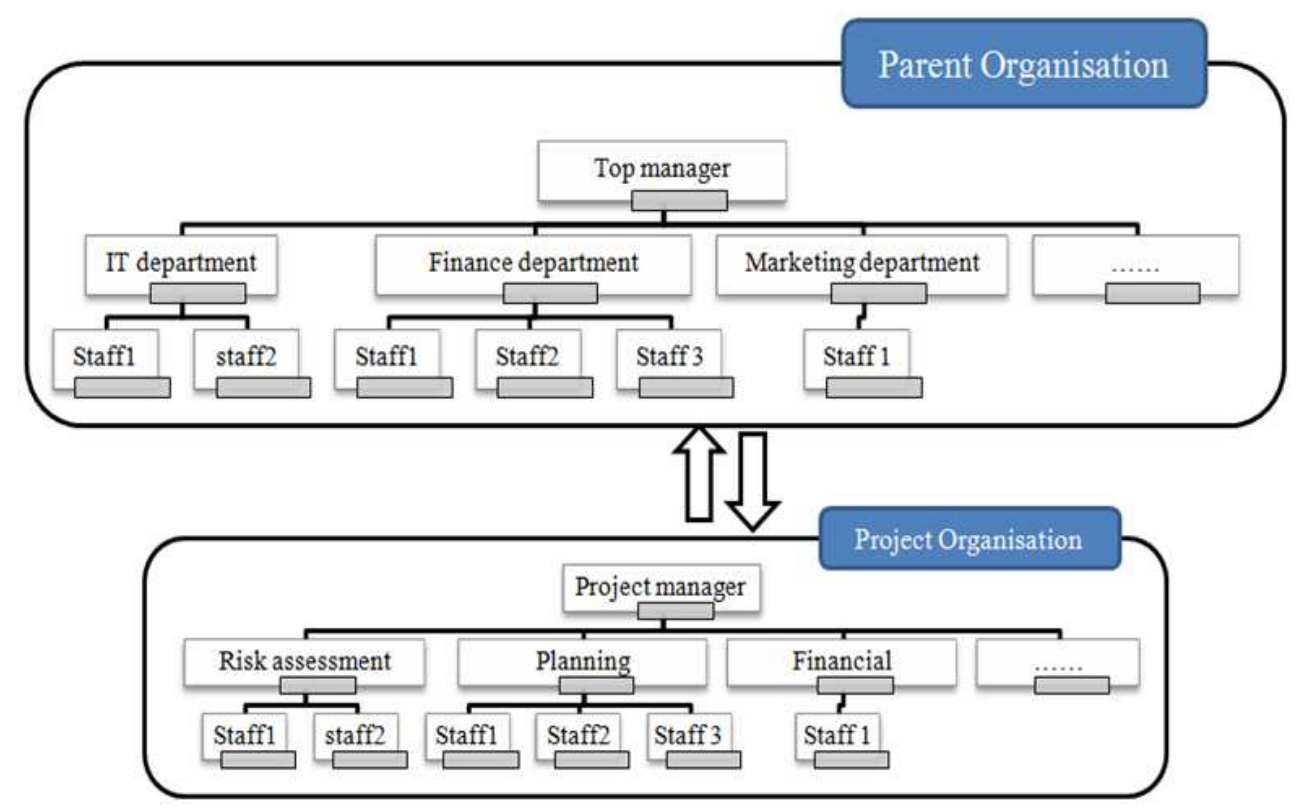

Fig. 2. Pure Project organisation structure (Larson and Gray, 2011)

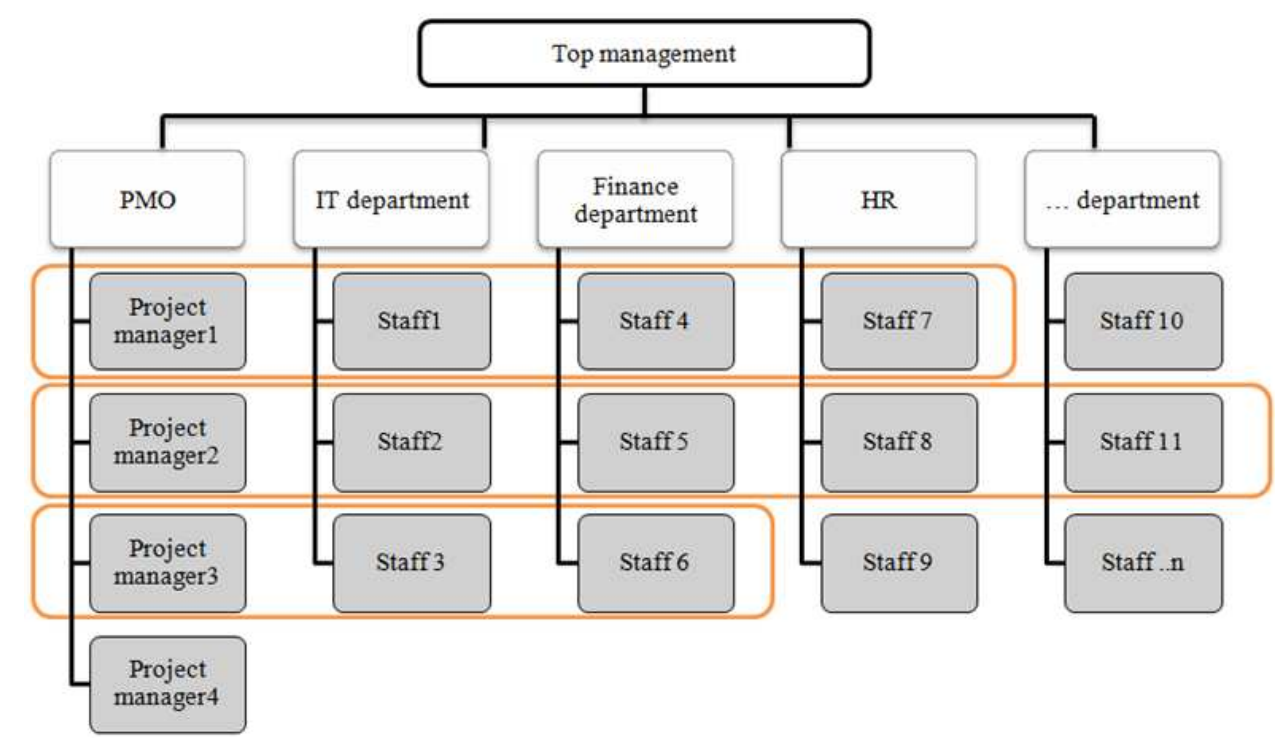

Fig. 3. Matrix organisation structure (Larson and Gray, 2011)

\section{SHIFTING TOA NEW STRUCTURE}

Mumford (1983) introduced a new approach to solving socio-technical problems when organisations adopt new systems. This approach is called The Effective Technical and Human Implementation of Computer-based Systems (ETHICS). The principal objective for ETHICS is the successful integration of company objectives with the needs of employees and customers (Mumford, 1983). ETHICS supports the role of organisation and people in implementing new systems, but its adaptation process is concerned with moving from one kind of organisational structure and state to another and the means by which this change is 
assisted to take place smoothly and successfully (Mumford, 1983). Martin (2010) has explained the organisational desire for change by:

- External factors, such as the activities of competitors and market

- Internal factors, such as the knowledge base, bureaucracy, technology, future plan and the size of the organisation

- Organisational capability, will and politics (Martin, 2010)

Larson and Gray (2011) has asserted the association between project success and the amount of autonomy and authority given to project managers is relatively robust in many sectors, but shifting to a new structure can lead to unexpected difficulties with organisations' resources and capital (Larson and Gray, 2011). Furthermore, (Larson and Gray, 2011; Moore, 2002) state several factors which affect the choice of structure and divide them into two categories, Organisation and Project-level factors. Hobbs and Ménard (1993) also state clearly several influential factors on the selection of structure, such as the size and effort of the project, strategic importance, integration needed, complexity level, budget and time constraints, stability of resource requirements. Larson and Gobeli (1987) revealed that using Matrix structure leads to a significant success level compared to other structures. Another study by (Gray et al., 1990) supported (Larson and Gobeli, 1987) by emphasising the use of Matrix (strong and balanced) over all construction projects over 14 countries. Further support was introduced by (Yang et al., 1997) that balanced Matrix was commonly used in successful construction andproduct development projects.

In sum, public organisations are considered as cohesive entities within one governmental authority. These entities interact and so changing one entity might be expected to influence other governmental entities' integration or cohesiveness.

\section{CONFLICT MANAGEMENT IN SOFTWARE DEVELOPMENT PROJECTS}

It is Inevitable that differences and disagreements occur in any fast-paced organisation, but unresolved conflicts between team members can be the most influential factor in destroying the effectiveness of that team more quickly or more completely (Humphrey,
1996). According to Sunny (Baker and Baker, 1992) conflict in project can be categorised into three types:

- Goal-oriented conflict; which is linked to the targetresults, performance specifications and criteria, priorities and project's objectives

- Administrative conflict; this type is attributed to the management structure and project management practices which involve roles, reporting relationships, responsibilities and authority for tasks

- Interpersonal conflict; this type results from differences in work ethics, styles and personalities of the participants (Baker and Baker, 1992)

Robinson et al. (1974) stated that structural conflicts can be reduced by clarifying or altering line of authority and responsibility as well as agreeing reporting relationships processes (Robinson et al., 1974). Recently, (Rahim, 2011) states that restructuring a project's organisation can resolve conflict to allow active participation and creative expression and more precisely, using strong Matrix forms work better during the execution and termination phases (Rahim, 2011). Such situations usually arise in Matrix structures, where functional managers may exert their authority over personnel who have been assigned to a specific project manager for the duration of the project (Robbins, 1974). Accordingly, since software development projects are principally treated with project management tools, administrative conflict commonly occursas in any other projects. An empirical study of conflict in software companies conducted by (Gobeli et al., 1998) revealed several facts in a software development setting as following:

- Unresolved conflict has a strong, negative impact on overall software product success

- Confrontation and collaboration will augment team member satisfaction

- Forcing employees will decrease their satisfaction and will have a greater negative impact at the project team level as opposed to the organisational level

- Project management practices should emphasize confrontation over "give and take" when conflict surfaces

\section{ORGANISATION STRUCTURE IN THE PUBLIC SECTOR}

Following the underpinnings of the beaurucratice management school by Max Weber's (1864-1920), hierarchical organisation structure is noticeably the 
most commonly adopted model in many public organisations (Swedberg and Agevall, 2005). Beaurucratists emphasise clear lines of authority and specific goals and objectives. Most public organisations adopt a functional structure with hierarchical authority lines and roles (Rainey et al., 1976). There are some assertions that public organisations have less flexibility and autonomy in making their own decisions than their private sector counterparts (Martin, 2010) and that where flexibility exists it will be limited to nonstrategic modifications (Rainey et al., 1976). Nontheless, (Umar et al., 2012) found that public sector is less capable to sign a successful partinership wth the private sector because of the laxity in projects' monitoring and observation (Umar; Idrus; Amila; Zawawi; Khamidi; 2012). When Matrix structures are implemented in hierarchical organisations, one of the most common characteristics is that a traditional, vertical hierarchy is overlaid by some form of lateral authority, influence, or communication (Ford and Randolph, 1992).

In many developing countries including Saudi Arabia, the public sector leads the employment market. In Saudi Arabia there are more than 1.2 million employees working for government agencies (SCDSI, 2013). These agencies' hierarchy and structure are managed strictly by the government through the ministry of civil services. However, each public organisation can cope with its projects'requirements in a way that leads to success by adopting (or creating) implicitly a proper project structure within the original parent organisation through making some permitted modifications. In many developing countries, competition among organisations is taking place in software development, although developing software is not their fundamental business. Accordingly, studying the impact of public organisations' structure on the progress of software development is a legitimate and significant target for our study in order to develop a structural model. Based upon this constructivist reasoning, two important questions were addressed in this study:

- What are the organisational obstacles that impede public organisations from implementing fast and flexible software projects

- How can public organisation overcome these obstacles in software development

\section{METHODOLOGY}

The aim for this study is to highlight the obstacles that impede software development within an organisational context. Reliable and honest results are required to identify the obstacles and hence to suggest a new organisational model that helps to overcome them.

\subsection{Sampling}

For the purpose of availability and applicability, Saudi Arabian organisations were selected to be the representative sample in this study as Saudi Government is leading most of the central software projects through its ministries. Therefore, five governmental organisations from Saudi Arabia public sector were chosen to be this study's sample. All the selected organisations provide domestic services to Saudi citizens through a diversity of software projects around Saudi Arabia. Participants were chosen by using probable stratified sampling as they were selected from different strata (Patton, 2005).

\subsection{Approach}

In this study, we need to answer critical questions regarding power conflicts, reporting relationships (including the delivery of requirements to IT departments and IT departments' reporting back on progress) and success in the delivery of software projects. Bell states "The approach adopted and the methods of data collection selected will depend on the nature of the inquiry and the type of information required" (Bell, 2005). We wish to understand not just what is happening in organisations but also why it was happening (Moore, 1983). We are investigating social phenomena that occur in the natural setting of real organisations rather than in an experimental setting and we wish to understand the experiences and views of participants in depth (Pope and Mays, 2008). We have therefore chosen to follow a qualitative approach with a selective study sample. Wilkinson (2002) found thatinterviews can be used when in-depth information is required, the subject matter is potentially sensitive and the issues under examination would benefit from development or clarification (Wilkinson, 2002). Therefore in-depth interviews were selected to answer this study's questions. The study sample consists of three layers of software project stakeholders; decision makers, IT projects managers and End users.

Semi-structured interviews were chosen in order to manage the direction of the interviews towards software development rather than other organisational issues (Wood, 1997). Each interview session was divided into three parts (the current situation in software development; the best organisation structure to suit the participants' organization; and then an evaluation of 
some existing and proposed project management practices). Piloting the questions was important to validate our questions and therefore three participants were interviewed separately and consequently some modifications were made to our original script. After the pilot sessions, 30 potential interviewees from 5 different public organisations (including all our three sample layers) were contacted and asked for a 30-min meeting session. 25 of them accepted our request; sample distribution is shown in Table $\mathbf{1 .}$

Interviews took place in Saudi Arabia and sessions were recorded on tapes and then transcribed into Arabic before being translated and transcribed into English for analysis.

\subsection{Analysis}

For the purpose of this study we used Relational Analysis which involves two stages: First identifying concepts and then exploring the relationships between these concepts (Navenec and Hirst, 2010). Erlandson (1993) argues that analysing interview data needs to be done through four elements: (1) Unitizing data. (2) Emergent category designation, (3) Negative case analysis. (4) Bridging, extending and surfacing data (Erlandson, 1993). Furthermore, Miles and Huberman (1994) distinguish three processes in the analysis of interview data: 1. Data reduction 2. Data display (summaries, diagrams and text-matrices). 3. Conclusion-comparing, contrasting, searching for patterns, triangulation (Miles and Huberman, 1994). In respect to the strategy used in interview analysis, Paterson (2010) has stated that a within-case analysis is used with in-depth interviews to have an in-depth exploration of every single organisation as a standalone entity (Paterson, 2010). Furthermore, cross-case analysis was conducted to identify the consistencies across these organisations and the reasoning for any convergence or divergences identified (Handfield and Melnyk, 1998; Huberman and Miles, 1994). Our within-case analysis has helped in identifying the organisation structure adopted by each organisation; this was achieved by investigating our participants' contributions from every organisation across the three sample layers. Accordingly, a qualitative evaluation through in-depth interviews has been conducted to have a clear insight on how requirements' delivery and power influence are being practiced at each organisation.

Thematic analysis was used in this study in order to pinpoint the most emergent patterns or "themes" at each organisation and then all the recorded phenomena and themes were linked with the adopted structure in that organisation. Bias avoidance has taken place by considering the most emergent themes at every organisation as the main characteristic of this organisation's structure. Project management skills were assessed by conducting a negative case analysis in order to identify the contradiction between the ideal and existing practices.

Any qualitative researcher should be concerned about validity and reliability while designing a study and analysing its results (Patton, 2005). Participants' answers were validated by asking the same questions throughout the three layers as shown in Fig. $\mathbf{4}$ and end users' opinions were matched with other layers' answers and linked to the structure being used in that organisation. Documentation was also used as a validation tool as it was gathered to identify the current organisation structure and compared with participants' interviews' contributions in order to highlight any contradiction or consensus information.

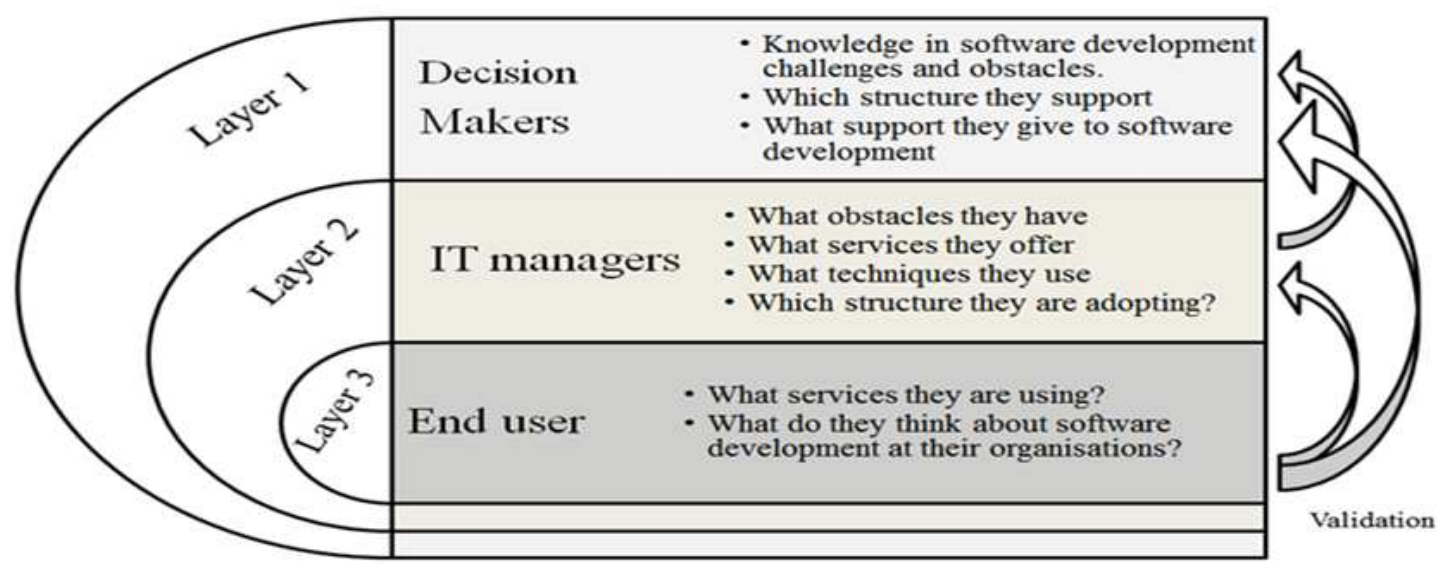

Fig. 4. Methodology and validation model 
Table 1. Sample distribution over several organisations

\begin{tabular}{llcr}
\hline & Decision maker & IT manager & End user \\
\hline Org. 1 & 1 & 2 & 2 \\
Org. 2 & 2 & 1 & 2 \\
Org. 3 & 2 & 1 & 2 \\
Org. 4 & 1 & 1 & 2 \\
Org. 5 & 2 & 2 & 2 \\
Total & 8 & 7 & 10 \\
\hline
\end{tabular}

In sum, this study aims to provide a real insight into the explicit impact of the adopted organisation structures adopted by Saudi government organisations on the software development process and whether this impact on software development occurred because of these structures or by happenstance. Because we were conducting interviews with three different types of people, a within-case analysis has been conducted in these interviews in order to link each sample's contributions to their counterparts from different layer and analyse them precisely.

\section{RESULTS}

This study questions were prepared and 25 interviews were undertaken in a period of 4 weeks. All interviewees were in some way involved in software development. The results of these interviews were drawn based on the interviewees' types (Decision makers, IT projects managers and End users). Table 2 summarises the results. It shows the structures found in each organisation and the themes that were identified from each type of interviewee.

\subsection{Decision Makers and Software Development Strategies and Support}

Our participants in this layer were from five different organisations (referred to as Org1 to Org5). Each participant was asked three questions. The first question was designed to measure their understanding of the challenges facing software development projects and the ways they cope with them; the second question was about the organisation structure that being adopted in their organisation; and the last question was about their support for and interactions with software development projects. Regarding the first question, participants were confident and optimistic about their future plans for software development projects because of the expected benefits from utilising technology power in their organisations. However, only two of them $(40 \%)$ have showed a high understanding level of the obstacles that might face software development, whereas other participants $(60 \%)$ showed a partial normal level of knowledge about the challenges of software development. Moreover, $(80 \%)$ four interviewees explained their enthusiasm by the high competition across all government's agencies in achieving the strategic targets of E-government programmes by the end of 2015 (Yesser, 2013). The second question tried to determine which organisation structure from our three models is being adopted in each organisation and whether they are trying to change their structure or not. Org1 was developing two IT projects concurrently and each project was being implemented in different project structure. The first project was within a Functional Structure as the IT department was the exclusive leader for this project, whilst the second project was being implemented in a Pure Project structure as the project was located in an external environment with a dedicated team and structure. Orgs 2 and 3 were purely Functional in structure as the IT department was leading all software development projects independently. Org 4 used a strong Matrix organisation structure managed by the IT department as they had been using Functional structure before their conversion to the new model. Their IT projects are monitored and directed by an internal Project Management Office under the supervision of IT department manager. Likewise, software projects in Org5 were conducted within a balanced Matrix structure through an internal PMO managed jointly from IT department and Functional department.

The last question asked about support for software projects at their organisations. A strong theme emerged from those who are adopting Functional structure. This theme consists of support, monitoring and direct management of software projects as the organisations rely on the IT department to accomplish these projects. Participants from Pure Project structures have been grouped under an indirect support theme, as they require an intermediary to inform them about software development progress and they give their support back through the same intermediary. Lastly, participants from Matrix structures have shown direct interaction with software projects' progress as the PMO frequently reports to them. However, project management skills have not been presented explicitly within the Functional structure adopters.

\subsection{IT Project Managers and the Current Software Development Process}

From the analysis of interview themes, IT managers from Functional structures have shown a high level of "power and control" over all their projects and over all other corresponding departments. Some themes emerged 
such as "Technical Confidence", "Resistance awareness", "we are facing managerial difficulties", "formal communication" and "bureaucratic processes". Different themes emerged from the IT managers in Pure Projects structures, where most of the observed expressions were "Deadline dates", "Team working and development", "work flexibility" and they did not present any negative points related to financial difficulties or managerial obstacles. Project managers in Matrix structures (both balanced and strong) showed high knowledge about project management practices, although a moderate theme emerged about "conflict" in many places in the interview.

\subsection{End Users and their Confidence in the Software Development Process}

End users were interviewed primarily to validate the interviews with decision makers and IT project managers. Interviewing different types of people from the same organisations was an indispensable part of this study in order to augment the validity of our participants' contributions throughout each adopted structure. In Functional structures, End users showed positive feelings towards the importance of technology and software projects; however, a few negative themes emerged in these interviews which are "Power", "Authority", "control", "inequality in promotions", "delay in projects", "unseen results", "and bureaucratic processes". These themes from End users in Functional structures partly contradict some of the Layer B (IT managers') contributions indicating a Power Conflict.

In a Pure Project structure, End users did not show any positive awareness about software development progress although they showed a moderate confidence level that IT projects would be delivered to them on time. The most common theme that emerged was "External team".

Interestingly, End users from Matrix structure organisations showed positive awareness of the project's progress and are aware of the hand-over dates which are reported by email from the PMO about the project increment. Each corresponding department also has at least one designated person in a software project to represent his department at that project, usually a domain expert from that department. A moderate theme emerged about an implicit competition among functional employees to be part of the PMO team to get more power and information.

\section{DISCUSSION}

By going through all the results from three layers of interviewees, several important points have been observed and these are discussed separately as follows:

\subsection{Software Development in Organisational Context}

From the results shown in Table 2, it has become clear that Functional Organisations are adopting a traditional command and control hierarchy administered in a formal and organised manner. Effort and ideas recognition was one of End users' concerns during the requirement gathering stage as IT members take the dominant roles and motivation; nevertheless, a lack of project management skills of IT managers might exaggerate this gap and conflict between end users and IT team members. Moreover, neither IT managers nor End users are highly confident that software projects would be accomplished within satisfactory bounds of time, cost and quality due to the long formal processes. In this structure, projects' flexibility and agility are impeded. This supports the view of (Ford and Randolph, 1992; Rainey et al., 1976) that lack of management of projects' stakeholders and requirements in functional structure increases the risk of power conflict and poor requirements' delivery. Functional organisation is primarily created to manage different type of business which are not focused on software development, therefore it shows weak points specific to software development.

Secondly, in a Pure Project structure small independent organisations showed signs of high professionalism in their practices and the parent organisation did not need to exert any influence over a project's implementation as long as the dedicated team were reporting as projected. As stated by (Larson and Gray, 2011), this organisation is meant to be created temporarily for projects that can be transferred back to the parent organisation, or for projects that have been conducted to help organisations through transition periods and so this structure might not be applicable for organisations with constant and permanent development requirements.

Lastly, the Matrix structures (strong and balanced) showed interactive and directive approaches in implementing software projects in Orgs 4 and 5 . Although IT project managers took the dominant role in this structure and this caused some power conflict within these two organisations, project progression and reporting systems were satisfactory from the perspective of end users. This structure was recognised and adopted in two different organisations from our sample, but it was influenced by the main framework of the organisation and so it has not always been implemented fully in eitherorganisation. If power distribution is not carefully managed then the matrix structure may be converted to a new functional department as our results show that conflicts still exist which might impede the delivery of project management practices. 
Table 2. Interviews Themes and results (grouped)

\begin{tabular}{|c|c|c|c|c|}
\hline Organisation & Structure & Decision makers layer 1 & IT managers layer 2 & End users layer 3 \\
\hline$\overline{\text { Org1 }}$ & Functional & $\begin{array}{l}\text { Supportive } \\
\text { E-gov competitor } \\
\text { Active management }\end{array}$ & $\begin{array}{l}\text { Sole control } \\
\text { Resistance awareness } \\
\text { Managerial obstacles } \\
\text { Projects are delivered } \\
\text { Bureaucratic and formal } \\
\text { communication channels } \\
\text { Technical confidence }\end{array}$ & $\begin{array}{l}\text { Conflict with IT } \\
\text { Mistrust with IT } \\
\text { Requirements ambiguity } \\
\text { Mistrust Project completion } \\
\text { Intellectual property }\end{array}$ \\
\hline & Pure Project & $\begin{array}{l}\text { Indirect support } \\
\text { Contractual skills } \\
\text { E-services competitor }\end{array}$ & $\begin{array}{l}\text { Deadline handover } \\
\text { Team working } \\
\text { Autonomy and flexibility }\end{array}$ & $\begin{array}{l}\text { Low awareness } \\
\text { Low participation }\end{array}$ \\
\hline Org2 & Functional & $\begin{array}{l}\text { Supportive } \\
\text { Active management }\end{array}$ & $\begin{array}{l}\text { Sole control } \\
\text { Resistance Awareness } \\
\text { Managerial obstacles } \\
\text { Informal communication needed }\end{array}$ & $\begin{array}{l}\text { Requirements ambiguity } \\
\text { Formal communication } \\
\text { Formal coordination } \\
\text { Intellectual property }\end{array}$ \\
\hline Org3 & Functional & $\begin{array}{l}\text { Supportive } \\
\text { E-gov competitor } \\
\text { Active management }\end{array}$ & $\begin{array}{l}\text { Power and control } \\
\text { Managerial obstacles } \\
\text { High PM skills } \\
\text { Delay reasoning }\end{array}$ & $\begin{array}{l}\text { Formal communication } \\
\text { Formal coordination } \\
\text { Power conflict }\end{array}$ \\
\hline Org4 & Matrix (strong) & $\begin{array}{l}\text { Supportive } \\
\text { PM knowledge } \\
\text { E-gov competitor } \\
\text { Interactive with IT } \\
\text { Through PMO }\end{array}$ & $\begin{array}{l}\text { Reporting process } \\
\text { High PM skills } \\
\text { Tasksawareness } \\
\text { Resistance awareness }\end{array}$ & $\begin{array}{l}\text { High participation } \\
\text { Weekly meeting } \\
\text { Direct communication } \\
\text { Conflict with their } \\
\text { functional managers }\end{array}$ \\
\hline Org5 & Matrix (balanced) & $\begin{array}{l}\text { PM knowledge } \\
\text { Indirect support } \\
\text { E-gov competitor }\end{array}$ & $\begin{array}{l}\text { High PM skills } \\
\text { Project awareness } \\
\text { Technical Confidence }\end{array}$ & $\begin{array}{l}\text { Moderate awareness } \\
\text { high participation } \\
\text { Conflict with their } \\
\text { functional managers }\end{array}$ \\
\hline
\end{tabular}

\subsection{The Impact of Organisational Structure on User Requirement Delivery}

Clarification of users' requirements differs between organisation structures. In a Functional structure, users' requirements take a 6-step journey from the end user to the developer as shown in Fig. 5, which is twice as long as the Matrix structure shown in Fig. 6. Our results confirm that End users in Functional organisations feel that the long communication chains and the formal processes required by IT managers often result in requirements documents that are ambiguous and difficult to correct or clarify.

Although a Pure Project structure is adopted only after the acceptance of clear and complete requirements, interviewees have revealed that its likely to look for fast and direct communication channel when any laterchanges in the requirements occur, however, delivering requirements changes has taken the journey as shown in Fig. 7.

In Matrix structure, fast, clear and direct requirements delivery was constructed with a flexibility level higher than functional and Pure Project structure as all project members were linked to the project manager directly.

\subsection{The Impact of Organisational Structure on Reporting Relationships}

According to Nasir et al. (2008), users participation and interaction in software deelopment stages has become an indespensable part in the development lifecycle and their active roles in reporting relationships can be one one of the project's success factors (Nasir et al., 2008) Reporting relationships vary from Functional structure (slow and formal) to Pure Project and Matrix (fast and direct). From our interviews, we found that reporting in a Functional structure takes the same behaviour as user requirements flow. Whereas in pure project, reporting happened as node-node reporting, this happens between two counterparts agents (Reporting Agents RA) in Parent organisation as well as in Pure Project organisation as shown in Fig. 8. End users are looking for fast and immediate reporting processes as they concern about software bugs and the interfaces defects. In addition they find explaining this issue technically is out of their roles in the organisation. Conversely, IT managers try to receive immediate reports as they are moving towards project's closure stage and going back could make changes more sophisticated. 
Mohammed A. Bindrees et al. / Journal of Computer Science 10 (12): 2593.2607, 2014

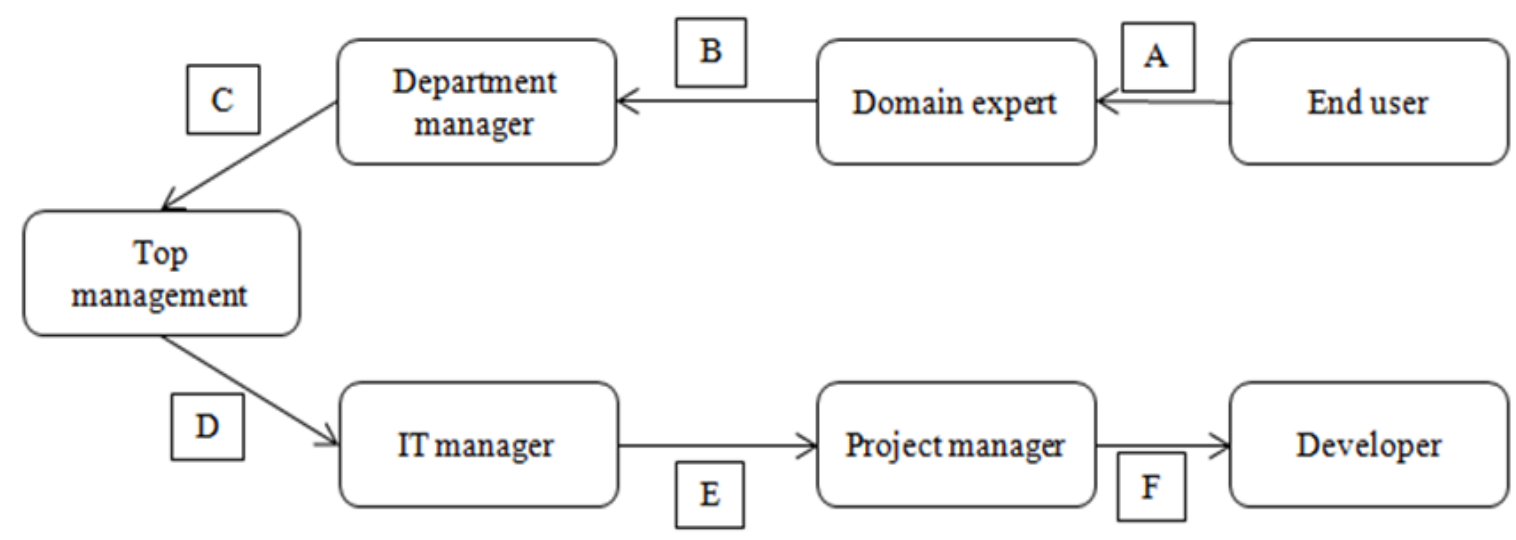

Fig. 5. Requirement journey in functional structure

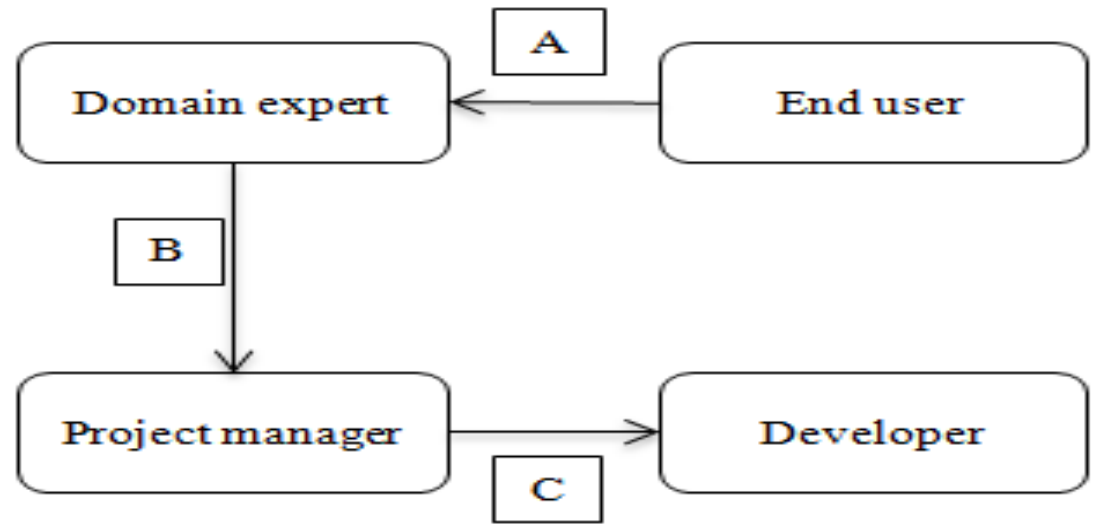

Fig. 6. Requirement journey in matrix

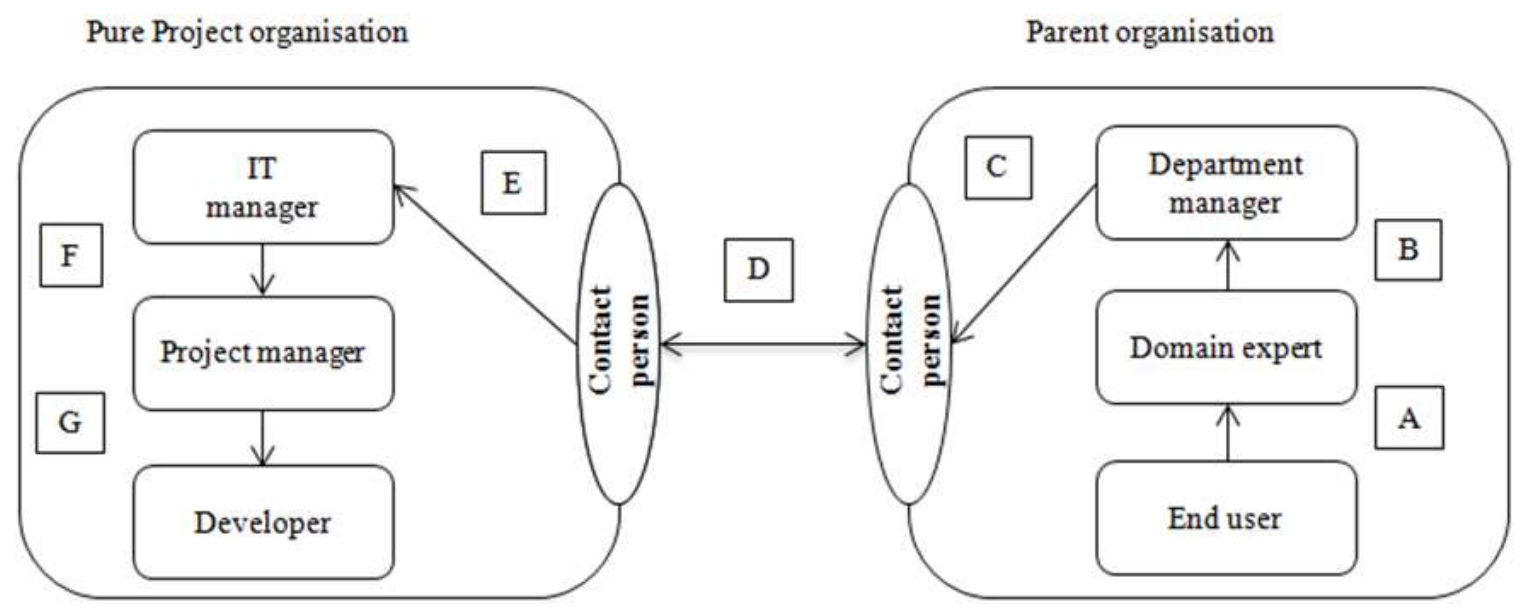

Fig. 7. Requirement journey in Pure project 


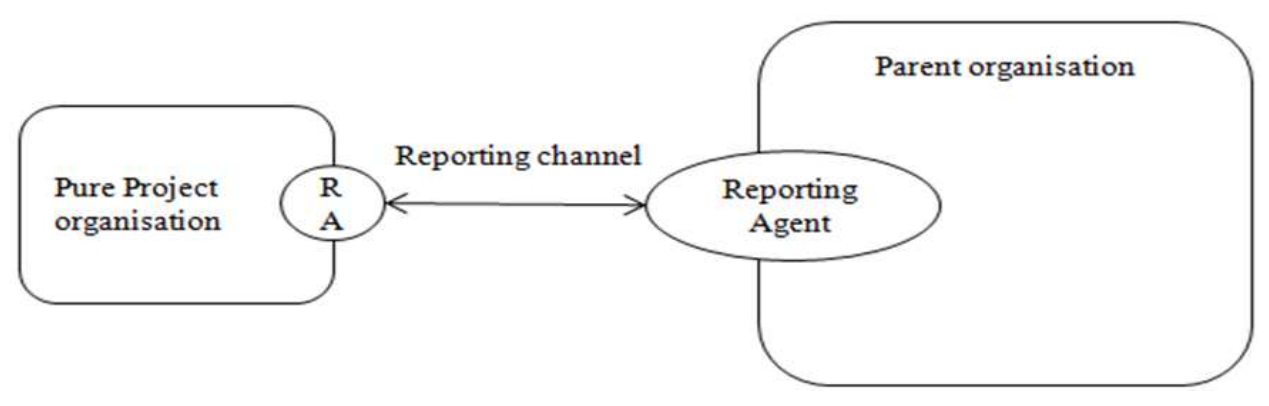

Fig. 8. Pure Project reporting relationships

Reportedly, in Matrix structure, reporting relationships take direct and instant message delivery by communicating project manager directly, he can then either response or forward these reports to the intended destination as shown in Fig. 9.

\subsection{Limitations in Organisational Structure}

From our results, public organisations are limited to adopting one of the mentioned structures (Functional, Pure Project and Matrix). Although Functional structure is the most commonly adopted paradigm in public organisations, the decision makers in this study showed awareness of and a positive attitude towards, the necessity to modify their organisational structures to accelerate software development. A Pure Project structure is reportedly considered a temporary and costly structure, but it can produce qualified on-demand software if requirements and plans are stable (Larson and Gray, 2011). Lastly, a Matrix structure was reported by our participants as more dynamic and interactive, but they also said that this model needs more professionalism in project management practices if it is to be adopted efficiently. A lack of experience in government authorities has led to weaknesses in Matrix structures.

In sum, Functional structure showed slowness and conflict in software development processes, Pure Project was reported as costly and ran the risk of violating the organisation's policies by creating a new small organisation and lastly, Matrix requires more professionalism and tools than are currently available to manage software projects seamlessly.

\subsection{Independent Project Management Office (IPMO) Structure's Concept and Validation}

Since all public organisations are pointedly restricted in changing their structures, they can accept tenders from companies in the project management consultation sector and so they could utilize these contracts to create an Independent Project Management Office (IPMO) to manage all organisations' projects effectively and directly including all software projects. Therefore we developed a new model called Independent Project Management Office (IPMO) as shown in Fig. 10.

The aim of this model is to apply project management practices within a solid organisational structure. It combines both Functional and Matrix structure in one paradigm to be managed by a 3rd party which will protect power distribution as well as the parent organisation's cohesive structure.

Our IPMO structure protects the authority level of each functional department to avoid power conflict and then provides a high level of project management practices in the organisation.

\subsection{IPMO Model Validation}

The proposed model (IPMO) is intended to facilitate the development processes and increase the quality of requirement delivery as well as reduce the potential conflict, which in turn would benefit diverse aspects of software projects. This structure has been validated by conducting short subsequent interviews with the decision makers' layer in order to ask them about the applicability of this model. A model-based diagram was prepared similar to Fig. 8 and then discussed with them. About 7 out of 8 decision makers supported this model, whereas the 8th expressed some reluctance because of the potential lack of software development experience in the 3rd party as they will be dealing with all kinds of projects in the same time. About 3 of decision makers raised a critical point as IT managers might show a low acceptance level of this model due to issues of control re-allocation.

The IPMO model is an alternative option to be taken into decision makers' account when discussing structural issues to reach better projects implementation. Therefore, it can be considered one of the available options for any Real Option analysis in making crucial decisions during project execution to minimise the losses and maximise the success rate (Copeland and Antikarov, 2001). 


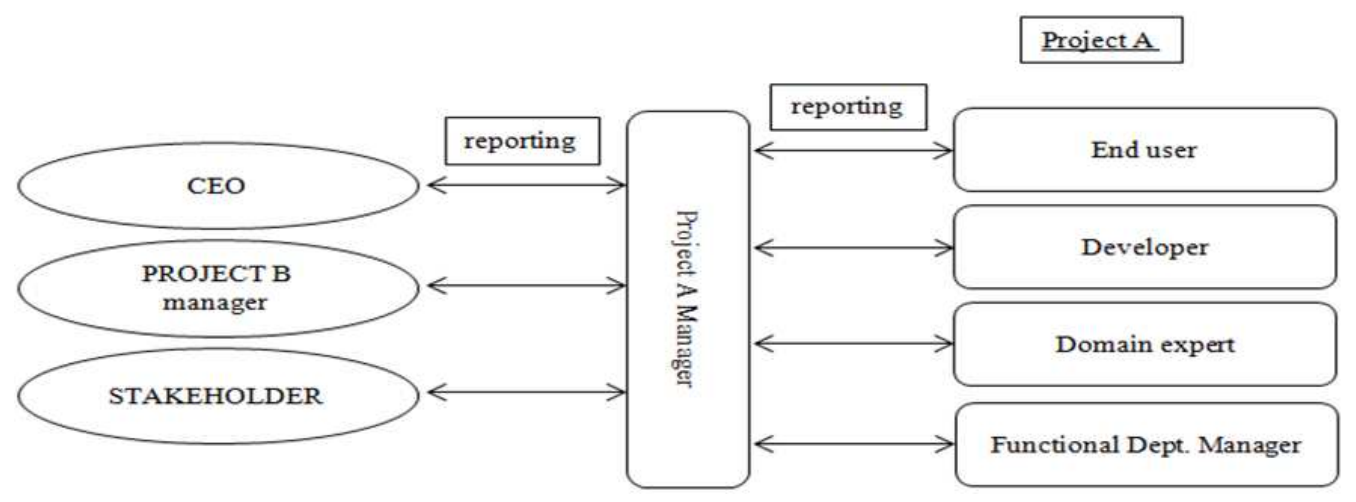

Fig. 9. Matrix reporting relationships

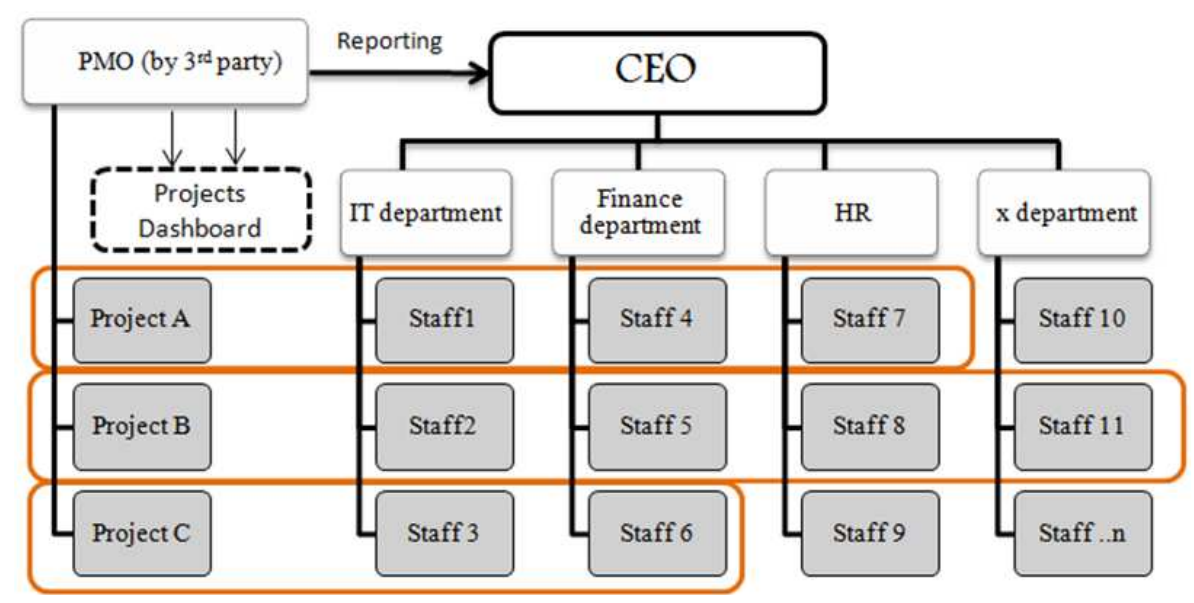

Fig. 10. IPMO structure

\section{CONCLUSION}

The main aim of this study is to investigate the influence of public organisations on software development progression. This study attempted to capture how organisational structure affects software development in workplace. In particular, it explains how software development projects are embedded in the workplace and shaped by organisational commands and processes. In-depth different interviews were conducted at different organisation levels which highlighted important difficulties in existing structures for software development, especially power conflicts, requirements ambiguity, complex reporting relationships and bureaucratic processes. Our within-case analysis revealed empirical evidence that power conflicts and problems in reporting relationships take place in all of the three major types of organisation (Functional, Pure Project and Matrix). More positively, leaders and decision-makers showed positive support for the conversion of public organisation structures to be more flexible and autonomous. A new model (IPMO) was developed and validated in order to augment the flexibility and accountability levels and thus reduce the power conflict within organisations during software projects' implementation. This model consists of an external consulting company to run a project management office; this will need to the elevate project management authority level to go between Top management and Functional departments, not on the same authority line with functional departments and hence eliminate interference between corresponding parties.

\section{ACKNOWLEDGMENT}

We would gratefully acknowledge Dr Hamad Al Ashaikh (the Vice minister of Ministry of Education in Saudi Arabia) for his constant support and contribution to 
this study. We would also thank Dr Saad Alfehaid (Debuty of Ministry of Education in Saudi Arabia) for his support and participation and we wish to thank all our study's participants for their time and sincere contributions.

\subsection{Author's Contributions}

All authors equally contributed in this work.

\subsection{Ethics}

This article is original and contains unpublished material. The corresponding author confirms that all of the other authors have read and approved the manuscript and no ethical issues involved.

\section{REFERENCES}

Al-Halak, A., W. Al-Karaghouli, A. Ghoneim and D. Koufopoulos, 2010. Knowledge management: Exploring the relationship between human capital and organisation structure capital. Proceedings of the European and Mediterranean Conference on Information Systems, Apr. 12-13, Abu Dhabi, UAE, pp: $1-11$.

Ashton, D.N., 2004. The impact of organisational structure and practices on learning in the workplace. Int. J. Train. Develop., 8: 43-53. DOI: 10.1111/j.1360-3736.2004.00195.x

Baker, S. and K. Baker, 1992. On Time/On Budget: A Step-By-Step Guide for Managing Any Project. 1st Edn., Prentice Hall, ISBN-10: 0136334474, pp: 320.

Baxter, G. and I. Sommerville, 2011. Socio-technical systems: From design methods to systems engineering. Interact. Comput., 23: 4-17. DOI: 10.1016/j.intcom.2010.07.003

Bell, J., 2005. Doing Your Research Project: A Guide for First-time Researchers in Education, Health and Social Science, 1st Edn., McGraw-Hill International, Maidenhead, ISBN-10: 0335224180, pp: 284.

Beynon-Davies, P., 2002. Information Systems: An Introduction to Informatics in Organisations. 1st Edn., Palgrave, Basingstoke, ISBN-10: 0333963903, pp: 595.

Burns, T.E. and G.M. Stalker, 1961. The Management of Innovation. 1st Edn., Oxford University Press, Oxford, ISBN-10: 0198288786, pp: 269.

Chen, T.Y., Y.M. Chen, C.B. Wang and H.C. Chu, 2009. Flexible authorisation in dynamic e-business environments using an organisation structure-based access control model. Int. J. Comput. Integrated Manufactur., 22: 2s25-244. DOI: $10.1080 / 09511920802209041$
Copeland, T. and V. Antikarov, 2001. Real Options: A Practitioner's Guide. 3rd Edn., Texere, New York, ISBN-10: 1587991861, pp: 370.

Cosh, A., X. Fu and A. Hughes, 2012. Organisation structure and innovation performance in different environments. Small Bus. Econ., 39: 301-317. DOI: 10.1007/s11187-010-9304-5.

Doherty, N.F., D. Champion and L. Wang, 2010. An holistic approach to understanding the changing nature of organisational structure. Inform. Technol. People, 23: 116-135. DOI: $10.1108 / 09593841011052138$

Erlandson, D.A., 1993. Doing Naturalistic Inquiry: A Guide to Methods. 1st Edn., Sage, Newbury Park, ISBN-10: 0803949375, pp: 198.

Ford, R.C. and W.A. Randolph, 1992. Cross-functional structures: A review and integration of matrix organization and project management. J. Manage., 18: 267-294. DOI: 10.1177/014920639201800204

Gobeli, D.H., H.F. Koenig and I. Bechinger, 1998. Managing conflict in software development teams: A multilevel analysis. J. Product Innovation Manage., 15: 423-435. DOI: 10.1111/15405885.1550423

Gray, C., S. Dworatschek, D. Gobeli, H. Knoepfel and E. Larson, 1990. International comparison of project organization structures: use and effectiveness. Int. J. Project Manage., 8: 26-32. DOI: 10.1016/02637863(90)90005-V

Handfield, R.B. and S.A. Melnyk, 1998. The scientific theory-building process: A primer using the case of TQM. J. Operations Manage., 16: 321-339. DOI: 10.1016/S0272-6963(98)00017-5

Hobbs, B. and P. Ménard, 1993. Organizational choices for project management.

Hobbs, B., M. Aubry and D. Thuillier, 2008. The project management office as an organisational innovation. Int. J. Project Manage., 26: 547-555. DOI: 10.1016/j.ijproman.2008.05.008

Huberman, A.M. and M.B. Miles, 1994. Data Management and Analysis Methods. In: Handbook of Qualitative Research. Denzin, N.K. and Y.S. Lincoln (Eds.,), CA: Sage Publications, Inc., pp: 428-444.

Humphrey, W.S., 1996. Managing Technical People: Innovation, Teamwork and the Software Process. 1st Edn., Pearson Education India, ISBN-10: 8177582712, pp: 352.

Kanter, R.M., 1984. Change Masters. 1st Edn., Simon and Schuster, ISBN-10: 0671528009, pp: 436. 
Larson, E.W. and C.F. Gray, 2011. Project Managment, the Managerial Process. 5th Edn., McGraw-Hill Irwin, New York, pp: 671.

Larson, E.W. and D.H. Gobeli, 1987. Matrix management: Contradictions and insights. University of California.

Martin, J., 2010. Key concepts in Human Resource Management. 1st Edn., SAGE, Los Angeles, ISBN10: 1446248224 , pp: 304.

Maylor, H., 1996. Project Management. London: Pitman Publishing.

Mcmillan, E., 2001. Considering organisation structure and design from a complexity paradigm perspective University of Cambridge: Institute of Manufacturing.

Miles, M.B. and A.M. Huberman, 1994. Qualitative Data Analysis. 1st Edn., SAGE, Thousand Oaks, ISBN10: 7814129214, pp: 338.

Miller, D., 1986. Configurations of strategy and structure: Towards a synthesis. Strategic Manage. J., 7: 233-249. DOI: 10.1002/smj.4250070305

Mintzberg, H., 1989. The Structuring of Organizations', Readings in Strategic.

Moore, D.R., 2002. Project Management: Designing Effective Organisational Structures in Construction. 1st Edn., Oxford, ISBN-10: 9780632063932, pp: 288.

Moore, N., 1983. How to do research. London: Library Association.

Mumford, E., 1983. Designing Human Systems for New Technology: The ETHICS Method. 1st Edn., Illustrated, Reprint, Manchester Business School, ISBN-10: 0903808285, pp: 108.

Nasir, M.H.N.M., M. Kamal and W.A.W. Rozali, 2008. Human computer interaction approach in developing customer relationship management. J. Comput. Sci., 4: 557-564. DOI: 10.3844/jcssp.2008.557.564

Navenec, C.L.L. and S.P. Hirst, 2010. Relational Analysis. In: Encyclopedia of Case Study Research, SAGE Publications. ISBN-10: 9781412956703.

Paterson, B.L., 2010. Within-Case Analysis. Encyclopedia of Case Study Research. SAGE. ISBN-10: 9781412956703.

Patton, M.Q., 2005. Qualitative research. Wiley Online Library.

Petersen, K. and C. Wohlin, 2010. The effect of moving from a plan-driven to an incremental software development approach with agile practices. Empirical Software Eng., 15: 654-693. DOI: 10.1007/s10664-010-9136-6
Pope, C. and N. Mays, 2008. Qualitative Research in Health Care. 3rd Edn., John Wiley and Sons, ISBN10: 1405173238, pp: 168.

Rad, P.F. and G. Levin, 2002. The Advanced Project Management Office: A Comprehensive Look at Function and Implementation. 1st Edn., CRC Press, ISBN-10: 1420000373, pp: 224.

Rahim, M.A., 2011. Managing Conflict in Organizations. 4th Edn., Transaction Publishers, New Brunswick, ISBN-10: 1412844258, pp: 342.

Rainey, H.G., R.W. Backoff and C.H. Levine, 1976. Comparing public and private organizations. Public Administrat. Rev., 36: 233-244.

Robbins, S.P., 1974.. Managing Organizational Conflict: A Nontraditional Approach. 1st Edn., Prentice-Hall, Englewood Cliffs, ISBN-10: 0135504910, pp: 156.

Robinson, J., W.J. Roy and R.A. Clifford, 1974. Conflict Management in Community Groups. New York, University of Illinois at Urbana-Champaign.

SCDSI, 2013. Saudi Central Department of Statistics and Information.

Sommerville, I., 2011. Software Engineering. 9th Edn., Addison-Wesley, Boston, MA USA.

Swedberg, R. and O. Agevall, 2005. The Max Weber Dictionary: Key Words and Central Concepts. 1st Edn., Stanford University Press, ISBN-10: 0804750955, pp: 344.

Umar, A.A., A. Idrus, N. Amila, A. Zawawi and M. Khamidi, 2012. Improving client internal capability to monitor public-private partnerships projects: A review. Am. J. Eng. Applied Sci, 5: 301-309. DOI: 10.3844/ajeassp.2012.301.309.

Wilkinson, D., 2002. The Researcher's Toolkit: The Complete Guide to Practitioner Research. 1st Edn., Routledge, ISBN-10: 1134608136, pp: 160.

Wood, L.E., 1997. Semi-structured interviewing. Intractions, 4: 49-61. DOI: 10.1145/245129.245134

Yang, M.L., K.B. Chuah, V.M. Rao Tummala and E.H. Chen, 1997. Project management practices in Pudong, a new economic development area of Shanghai, China. Int. J. Project Manage., 15: 313319. DOI: $10.1016 / \mathrm{S} 0263-7863(96) 00084-1$

Yesser, 2013. Saudi e-Government Program. 